\title{
O SUJEITO E SEUS MODOS DE GOZO
}

\author{
Christian Hoffmann
}

Psicanalista, professor de psicopatologia clínica na Sorbonne Paris Cité, Universidade de Paris Diderot, Codiretor da Escola Doutoral de Pesquisas em Psicanálise. Pesquisador no Centre De Recherches Psychanalyse, Médecine et Société (CRPMS).

Tradução: Pedro Henrique Bernardes Rondon

Psicanalista, membro efetivo da Sociedade de Psicanálise da Cidade do Rio de Janeiro (SPCRJ). Membro efetivo da Associação Brasileira para o Estudo da Psicologia Psicanalítica do Self (Abepps).

RESUMO: Mostra-se como a interioridade psíquica e corporal do sujeito se articula ao social. Considerando-se que o sujeito teria um modo peculiar de gozo, elabora-se a ideia de que ele teria uma ética da responsabilidade. Pretende-se sustentar que a formação sintomática, não somente implica o sofrimento, mas também uma operação de 'cisão' no ser do sujeito. Não se reduzindo à própria imagem, nem à sua palavra, ele vive num mundo de símbolos cuja articulação se faz por meio do discurso social, permitindo uma articulação entre sua subjetividade e seu modo singular de gozo. Distingue-se um gozo sexual de outro mais primário, dimensão de destruição interna não erotizada.

Palavras-chave: Sujeito, circuito pulsional, gozo, ética, responsabilidade.

ABSTRACT: The subject and his modes of jouissance. The article shows how the psychic and bodily interiority of the subject articulates to the social. Considering that the subject would have a peculiar mode of jouissance, the article develops the idea that this subject would have an ethics of responsibility. It argues that the symptomatic formation not only implies suffering, but also an operation of "splitting" in the subject's being. Not reducing himself to his own image, or to his speech, he lives in a world of symbols whose articulation is made through a social discourse, allowing an articulation between his subjectivity and his unique mode of jouissance. A sexual jouissance is distinguished from another one which is more primary, an internal dimension of a non-eroticized destruction.

Keywords: Subject, drive circuit, jouissance, ethics, responsibility. 
$\mathrm{V}$ ou desenvolver a ideia de que para a psicanálise o sujeito tem uma ética da responsabilidade (HOFFMANN, 2007) por seu modo peculiar de gozo.

Para isso, vou inicialmente me prender ao Corte Freudiano do sujeito.

Encontramos as premissas de uma concepção psicanalítica do sujeito em Freud, a propósito das pulsões e especialmente quando se trata do retorno pulsional - esse retorno necessário ao desenvolvimento da pulsão pela passagem da forma passiva à forma ativa, entre, por exemplo, "ver" e "exibir-se".

O outro tempo da pulsão no qual se indica o sujeito é o do "outro sujeito", como Freud o chama, aquele que deve entrar no circuito pulsional para que sua satisfação possa se produzir. Essa etapa da relação com o outro pela entrada de outro sujeito, parceiro, no fechamento do circuito pulsional mostra como a interioridade psíquica e corporal do sujeito se articula ao social.

Mas é no seu último texto, sobre a Ichspaltung (FREUD, 1938/1985), que Freud nos dá não apenas a solução para a recusa da feminilidade como 'rochedo da castração’ e da análise para os dois sexos, mas é aí que nos familiariza com a noção de sujeito do inconsciente às voltas com a pulsão, o gozo e as estruturas sociais, que se manifestam especialmente pelo interdito.

Nesse derradeiro texto escrito em 1938, Freud introduz o corte no ser. O Ich da Spaltung se deixa traduzir pelo "corte" ou a "cisão" do "ser". Por exemplo, a expressão Meines ganzes Ich se traduz por "Todo meu ser”. Pode-se completar pelo ser do "Eu” [Je], ou do sujeito. Essa divisão entre o enunciado e a enunciação não deveria nos incomodar.

Tal divisão do sujeito é a descoberta freudiana da solução para a recusa da feminilidade e para o seu rochedo analítico, a saber: diante de um trauma psíquico como um perigo psíquico ligado à busca de uma satisfação pulsional, quando se apresenta a escolha: a) renunciar à satisfação reconhecendo o perigo, ou b) tenegar a realidade do perigo e manter a satisfação.

A criança responde a essa situação conflituosa com duas posições opostas. Por um lado, recusa a realidade do perigo e não se deixa interditar nada; e, por outro, simultaneamente reconhece essa realidade, transformando em sintoma a angústia despertada por esse perigo.

A solução por meio do sintoma custa não apenas o preço do sofrimento, no qual o gozo nos reconhece, mas também o preço de uma “cisão" no ser do sujeito. Não há cura a esperar dessa divisão do sujeito, cujo núcleo é constituído pela pulsão e por sua satisfação, o gozo e os perigos da estrutura social. Em suma, como hoje reconhecemos, não há sujeito sem sintoma, isto é, sem gozo.

O sujeito lacaniano se fundamenta nessa Ichspaltung freudiana. Ele se define em primeiro lugar pelo significante do desejo da mãe que se encarna no falo. Esse falo que preexiste ao sujeito é o significante do desejo da mãe. 
O sujeito recoberto por esse significante ao qual seu ser está identificado vai se encarnar em seu corpo, incorporando sua imagem no espelho da mãe que o investiu de sua libido. Daqui por diante ele tem um corpo e está pronto a construir sua subjetividade no laço social em tensão entre seu semelhante no espelho, e o Outro, a figura da alteridade absoluta, mais além do espelho e do muro da linguagem, esse Outro do qual ele espera, em troca de sua palavra, um retorno de sua própria mensagem numa forma invertida. Em suma, um Outro suposto saber melhor do que ele o que é feito da verdade em sua palavra.

Esse sujeito que não se reduz à sua imagem fundadora de seu eu, nem à sua palavra, vive num mundo de símbolos articulados pelo discurso social e que lhe permitem articular sua subjetividade e seu modo de gozo, e em relação ao qual sabemos agora que o sujeito tem a responsabilidade, a da sua divisão subjetiva que é a resultante da escolha de seu modo de gozo.

Proponhamos agora a questão de: como isso goza? Muito cedo Lacan substituiu o Es freudiano pelo sujeito. Esse isso, que não é o eu [moi], para Freud é constituído por tudo o que o ser traz ao nascer e que constitui o gozo do vivo. Observemos ainda uma vez essa noção de "ser" nos últimos escritos de Freud, notadamente em seu "Esboço de psicanálise".

O “isso" nos leva diretamente ao corpo que goza, sem levar em conta qualquer consideração quanto ao sexo. Esse gozo que Lacan chamou de fundamental ou de mortal (LACAN, 1971, apud JADIN \& RITTER, 2009) se opõe ao gozo sexual, uma vez que não é cingido por um limite. Esse gozo toma emprestado o caminho em direção à morte (LACAN, 1969-1970/1991, p.17-18), é dirigido contra o corpo próprio ou contra o do outro. Em suma, gozar de um corpo, como diz Lacan, consiste, então, na maioria das vezes, em demoli-lo (LACAN, 1971-1972/2011).

Esse gozo mortal do vivo se articula no inconsciente com a pulsão de morte, com seu jogo de repetição. E é por intermédio da linguagem, à medida que o inconsciente é constituído pelos traços das experiências infantis de gozo, que a busca de gozo vai se articular ao traço significante que, como todo traço, veicula a significação da perda.

Essa ancoragem no gozo mortal no inconsciente pela produção linguageira da significação da perda de gozo introduz o gozo sexual.

O gozo sexual é chamado "gozo fálico" por Lacan, porque o gozo mortal se sexualiza pelo falo. O falo, desde a Grécia antiga, deve ser entendido como o significante do desejo que introduz a significação da perda e, consequentemente, o limite na busca do gozo.

O que diz acertadamente o filósofo do Iluminismo Julien Offroy de La Mettrie em $A$ arte de gozar: "Se perdi meus dias na volúpia, ah! Divindades, deem-mos de volta, para que eu os perca novamente!” (DE LA METTRIE, 2011). 
O corpo que fala e que goza, à medida que é construído a partir do discurso que organiza o laço social, nos convida agora a interrogar-nos acerca de como isso goza no social?

Tomemos a questão da violência e da pornografia (ANDRÉ, 2011) e procuremos compreender por que hoje em dia há um crescimento do poder desses dois fenômenos no social.

Ninguém vai contestar que nosso laço social é marcado por uma exigência de gozo que impele a um sempre-mais-de-sexo, em detrimento de uma sexualidade, sinônimo de erotismo. Essa ausência de Eros no gozo abre o campo à pulsão de morte pela dessexualização do laço social.

A vontade de gozar se opõe ao desejo e ao revestimento pelo significante fálico da pulsão que limita o gozo por sua sexualização. Dessa maneira podemos distinguir o gozo sexual de outro gozo mais primário que é o do vivo, em que o corpo goza num autismo que franqueia o acesso à "fúria destrutiva", como Freud indicava no seu Mal-estar na civilização, ao evocar a inquietante "agressão e destruição não erotizadas".

A pulsão de morte se apodera do terreno liberado por um laço social que se submete à palmatória da vontade de gozar ao ritmo das leis do mercado e do sempre-mais de consumo de objetos que passam depressa demais do up ao down do mercado, o que só faz excitar ainda mais a exigência de gozo.

A pornografia e a violência preparam o terreno para um sempre mais de gozar de um corpo dessexualizado pela ausência do investimento libidinal do laço.

Essa raiva prazerosa da violência que engloba a pornografia encontra seu mestre num supereu social que exige um gozo a qualquer preço, até a morte.

Em suma, uma vez que a política não promove um laço social à volta de alguns valores como a singularidade, a reciprocidade e a comunalidade (ROSANVALLON, 2011), que formam o tecido do político e da interioridade cidadã do sujeito, então a violência dessexualizada, quer dizer, sem limite, encontra seu gozo nessa desertificação.

Um dos traços facilmente determináveis hoje em dia no nosso laço social é o desinvestimento libidinal do trabalho. Isso coloca a burguesia dos assalariados em grande dificuldade e boa parte da juventude sofrendo a falta de investimento libidinal no saber (HOFFMAN \& BIRMAN, 2011), sem esquecer as derivas políticas ligadas a esse enfraquecimento da classe média dos professores, psicanalistas, e outros cidadãos.

A psicanálise não é uma ética do gozo que prometeria um novo desejo criativo na cultura ao sujeito que se apodera de seu corpo desenvolvendo novas estratégias de gozo, como era o profundo anseio de M. Foucault. De certa maneira, podemos constatar o fracasso do projeto de Foucault que não conseguiu evitar o isolamento identitário à volta das novas formas de gozo, em suma, na 
construção dos egos. Em compensação, a psicanálise pode ajudar um sujeito a se livrar de um peso de gozo, donde a ideia de Lacan de que em cada analisante há um aluno de Aristóteles.

O que não deixa de ter alguma ressonância política, pelo fato de o efeito que se pode esperar de uma análise sobre um sujeito que exerce um poder é que seja o inverso de um Alcebíades - quer dizer, que goze menos do poder e assim possa consagrar seu desejo à coisa pública.

Recebido em 5/1/2012. Aprovado em 25/3/2012.

\section{REFERÊNCIĀS}

ANDRÉ, S. (2011) No sex, no future. Paris: La Muette.

FREUD, S. (1938/1985) "Le clivage du moi dans le processus de defense"

In: Résultats, idées, problèmes. Paris: PUF.

HOFFMAN, C. (2007) Des cerveaux et des hommes. Paris: Érès.

\& BIRMAN, J. (2011) L'autonomie des universités et la nouvelle condition étudiante. La Célibataire, n. 23. Paris: EDK.

JADIN, J.-M. \& RITTER, M. (2009) La jouissance au fil de l'enseignement de Lacan. Paris: Érès.

LACAN, J. (1969-1970/1991) L'envers de La psychanalyse, Le Séminaire, livre XVII. Paris: Le Seuil.

. (1971-1972/2011) ... ou pire, Le Séminaire, livre XIX. Paris:

Seuil.

LA METTRIE, J. O. (1751/2011) L’art de jouir (anon.).

ROSANVALLON, P. (2011) La société des égaux. Paris: Seuil.

Christion Hoffmann

hoffmann.ch@wanadoo.fr

Pedro Henrique Bernardes Rondon

phbrondon@gmail.com 